\title{
Calculating the Probability of Constitutional Isomers of Pentane
}

Mary-Margaret Dare

University of South Florida

\author{
Advisors: \\ Arcadii Grinshpan, Mathematics and Statistics \\ Matthew Saunders, Cell Biology, Microbiology and Molecular Biology \\ Problem Suggested By: Catherine Boshra, Chemistry
}

Follow this and additional works at: https://digitalcommons.usf.edu/ujmm

Part of the Mathematics Commons

UJMM is an open access journal, free to authors and readers, and relies on your support:

Donate Now

\section{Recommended Citation}

Dare, Mary-Margaret (2021) "Calculating the Probability of Constitutional Isomers of Pentane," Undergraduate Journal of Mathematical Modeling: One + Two: Vol. 12: Iss. 1, Article 6.

DOI: https://doi.org/10.5038/2326-3652.12.1.4940

Available at: https://digitalcommons.usf.edu/ujmm/vol12/iss1/6 


\title{
Calculating the Probability of Constitutional Isomers of Pentane
}

\begin{abstract}
Depending on the reagent, and orientation of collisions within a chemical reaction, organic molecules can be present as different constitutional isomers of the same molecule. We can analyze the likelihood of getting a mixture of pentane with certain conformers. Based on this, we find that there are 16 potential conformers, but 13 are identical structures, meaning only three are distinct from each other. Using the product rule, we then demonstrate how to go about calculating the probability of specific conformers, including specific identical structures, being present in a mixture, and then we demonstrate that process is strictly within the three different conformers.
\end{abstract}

Keywords

Organic molecule, constitutional isomer, pentane, conformer, identical structures

Creative Commons License

(c) (i) (2)

This work is licensed under a Creative Commons Attribution-Noncommercial-Share Alike 3.0 United States License. 


\section{PROBLEM STATEMENT}

Determine the amount of constitutional isomers of pentane, and the likelihood of different conformers being present in a given solution.

\section{MOTIVATION}

For organic molecules as a whole, most of them can rearrange into multiple conformers depending on the orientation of collisions within a chemical reaction. Some structures are more stable than the others and thus each conformer has different chemical properties. Between being used in synthesizing adhesives, as fuel sources, and cleaning agents, pentane has a wide variety of uses and thus it is present in many everyday items or chemicals. However, due to the different structures of pentane, certain structures are more stable than others and thus certain constitutional isomers are needed for certain uses as opposed to the other conformers. Because of this, it is imperative to know how many of them can be made and the probability of each respective conformer of the molecule.

\section{MATHEMATICAL DESCRIPTION AND SOLUTION APPROACH}

Pentane is composed of 5 different carbons and 12 different hydrogens. The carbons can randomly assemble by bonding together to form the molecule, which dictates the actual structure of pentane, with the hydrogens being present to give each carbon a full octet of valence electrons. This means that only the carbons are relevant in determining the overall molecular structure. The basic structure of pentane with the carbons labeled is as follows: 


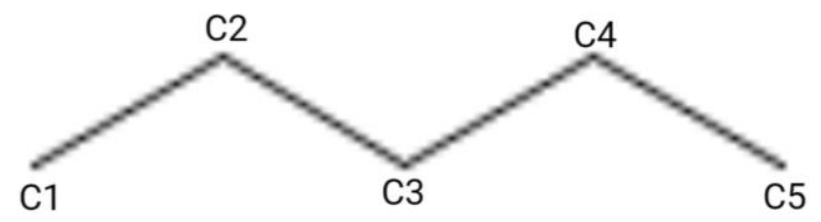

Figure 1: Basic Structure of Pentane

If the numbering of the carbons remains the same regardless of the placement of any substituents, the resulting conformers can be drawn as follows by placing $\mathrm{C} 1$ onto the other carbons, where the overall likelihood of $\mathrm{C} 1$ being the substituent is $1 / 5$ :

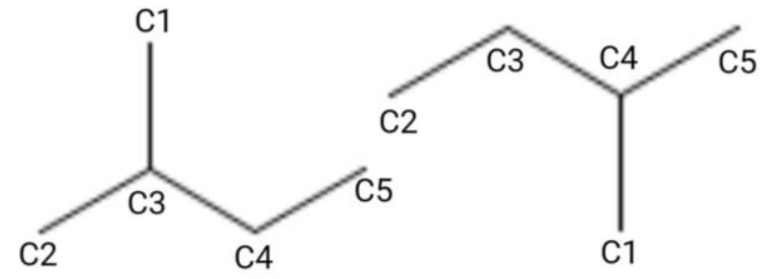

Figure 2: C1 Conformers

The resulting conformers can be drawn as follows by placing $\mathrm{C} 2$ onto the other carbons, where the overall likelihood of C2 being a substituent is 1/5:

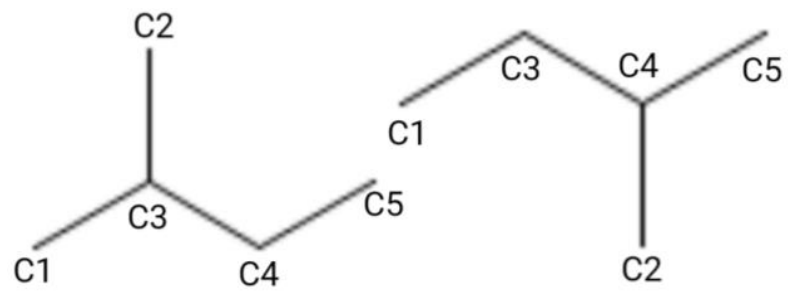

Figure 3: C2 Conformers

The resulting conformers can be drawn as follows by placing $\mathrm{C} 3$ onto the other carbons where the overall likelihood of $\mathrm{C} 3$ being a substituent is 1/5: 


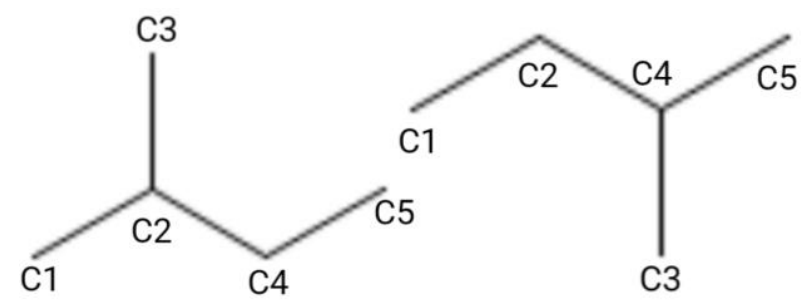

Figure 4: C3 Conformers

The resulting conformers can be drawn as follows by placing $\mathrm{C} 4$ onto the other carbons where the overall likelihood of $\mathrm{C} 4$ being a substituent is $1 / 5$ :

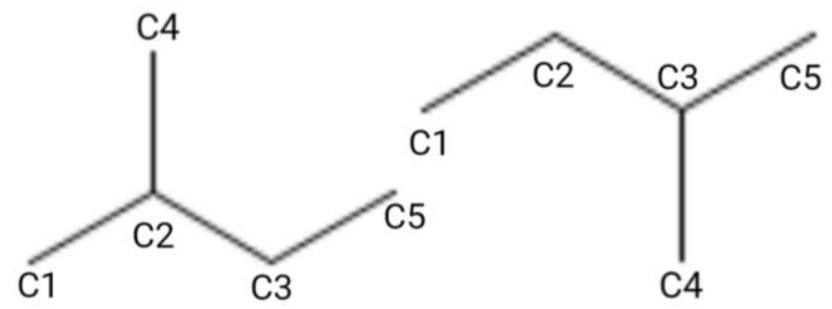

Figure 5: C4 Conformers

The resulting conformers can be drawn as follows by placing $\mathrm{C} 5$ onto the other carbons where the overall likelihood of $\mathrm{C} 5$ being a substituent is $1 / 5$ :

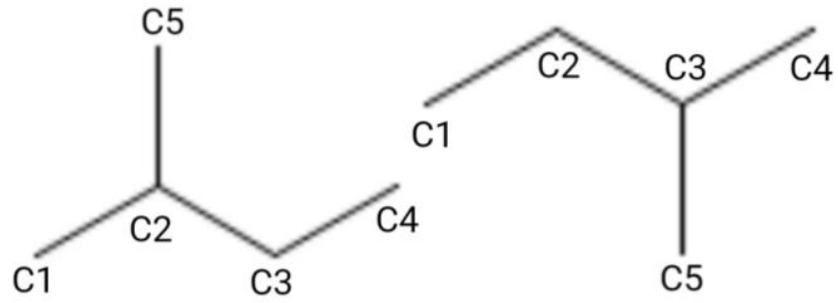

Figure 6: C5 Conformers

One other type of conformer can be made, by creating a carbon with the other 4 carbons 
bonded to a central carbon $(\mathrm{C} 1, \mathrm{C} 2, \mathrm{C} 3, \mathrm{C} 4$, or $\mathrm{C} 5)$ as shown:

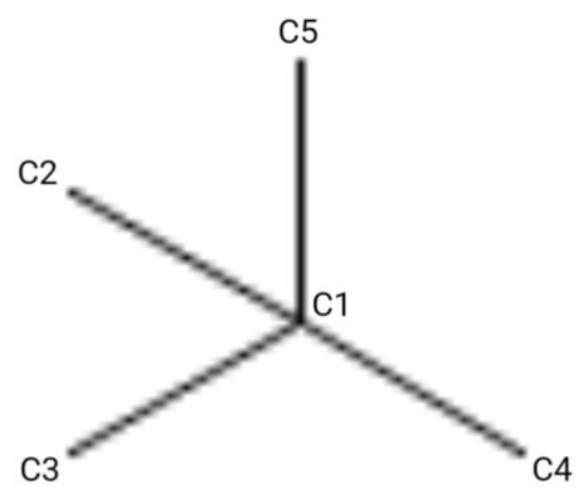

\section{Figure 7: Tetrahedral Conformer (C1)}

However, the conformers that are neither a five carbon chain nor a tetrahedral structure are all considered to be identical. All of the conformers with one substituent contain a carbon as their one substituent, meaning that the rotating of the structure in some way results in an identical structure. Similarly, the tetrahedral structures are all identical structures, with all of them having a central carbon bonded to 4 other carbons. Because of this, there are actually only 3 different conformers as shown below, with the corresponding probability found by combining the probabilities of each individual identical structure:
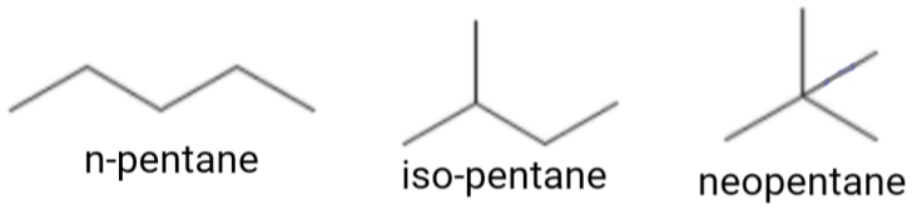

Figure 8: Pentane Conformers

$$
\text { n-pentane }=1 / 16, \text { iso-pentane }=10 / 16, \text { neopentane }=5 / 16
$$

Now knowing all of the possible conformers that deviate from the original structure of pentane, the product rule can be applied in order to determine the likelihood of a substituent being placed on a given carbon. The product rule is as follows, where $\boldsymbol{P}_{p}$ is the total fractional 
percentage of a given scenario, $\boldsymbol{P}_{\boldsymbol{n}}$ is the fractional percentage of one aspect of the overall scenario:

$$
\boldsymbol{P}_{p}=\boldsymbol{P}_{1} * \boldsymbol{P}_{2} * \boldsymbol{P}_{3} * \ldots * \boldsymbol{P}_{n}
$$

\section{DISCUSSION}

Taking the established fractional percentages from Table 1 and applying the product rule of probability, it becomes simple to calculate the probability of specific constitutional isomers being present in a solution of pentane.

$C 2$ on $C 3, C 4$ on $C 2$, and $C 3$ tetrahedral constitutional isomer pentane mixture probability: $[(1 / 2) *(1 / 5)] *[(1 / 2) *(1 / 5)] *(1 / 15)=(1 / 10) *(1 / 10) *(1 / 15)=1 / 1500=.00067 * 100 \%=.067 \%$ $C 3$ on $C 2, C 5$ on $C 2$, and $C 3$ on $C 2$ isomer pentane mixture probability:

$[(1 / 2) *(1 / 5)] *[(1 / 2) *(1 / 5)] *[(1 / 2) *(1 / 5)]=(1 / 10) *(1 / 10) *(1 / 10)=1 / 1000=.001 * 100 \%$ $=.1 \%$

Any tetrahedral structure, and any substituent on $C 3$ isomer pentane mixture probability: $(5 / 15) *(4 / 10)=20 / 150=.133 * 100 \%=13.3 \%$

There can be any combination of constitutional isomer mixtures, and the probability of producing a specific mixture can be calculated by multiplying all of the probabilities of the desired conformers, as stated by the product rule.

As stated, however, constitutional isomers are defined as different structures made of the same amount of carbons. Based on this, the fractional percentages change, but the overall application of the product rule remains the same.

Neopentane and n-pentane mixture probability:

$(5 / 16) *(1 / 16)=5 / 256=.0195 * 100 \%=1.95 \%$ 
Neopentane and iso-pentane mixture probability:

$(5 / 16) *(10 / 16)=50 / 256=0.195 * 100 \%=19.5 \%$

\section{CONCLUSION}

Knowing the potential constitutional isomers present within an organic solution is extremely important, seeing as different conformers have different properties. Some properties are more or less stable than the others, meaning that different conformers are better for different uses than the other conformers. The same approach can be applied to more complex nonpolar organic molecules as well.

\section{REFERENCES}

Stereoisomers. (n.d) Yale Department of Chemistry.

http://ursula.chem.yale.edu/ chem220/chem220js/STUDYAIDS/isomers/isom_intro/isomer.html

(Accessed May 4, 2021).

National Center for Biotechnology Information (2021). PubChem Compound Summary for CID

8003, Pentane. https://pubchem.ncbi.nlm.nih.gov/compound/Pentane (Accessed May 4, 2021).

Draw Chemical Structures (n.d). Chem Space. https://chem-space.com/search (Accessed May 4, 2021). 
Appendix: Table 1

\begin{tabular}{|c|c|}
\hline Constitutional Isomer & Probability \\
\hline $\mathrm{C} 1$ on $\mathrm{C} 3$ Conformer & $1 / 10,1 / 16$ \\
\hline $\mathrm{C} 1$ on $\mathrm{C} 4$ Conformer & $1 / 10,1 / 16$ \\
\hline C2 on C3 Conformer & $1 / 10,1 / 16$ \\
\hline $\mathrm{C} 2$ on $\mathrm{C} 4$ Conformer & $1 / 10,1 / 16$ \\
\hline $\mathrm{C} 3$ on $\mathrm{C} 2$ Conformer & $1 / 10,1 / 16$ \\
\hline C3 on C5 Conformer & $1 / 10,1 / 16$ \\
\hline $\mathrm{C} 4$ on $\mathrm{C} 2$ Conformer & $1 / 10,1 / 16$ \\
\hline C4 on C3 Conformer & $1 / 10,1 / 16$ \\
\hline C5 on C2 Conformer & $1 / 10,1 / 16$ \\
\hline C5 on C3 Conformer & $1 / 10,1 / 16$ \\
\hline C1 Tetrahedral Conformer & $1 / 5,1 / 16$ \\
\hline C2 Tetrahedral Conformer & $1 / 5,1 / 16$ \\
\hline C3 Tetrahedral Conformer & $1 / 5,1 / 16$ \\
\hline C4 Tetrahedral Conformer & $1 / 5,1 / 16$ \\
\hline C5 Tetrahedral Conformer & $1 / 5,1 / 16$ \\
\hline
\end{tabular}

